\title{
Predictors of Variation in Maternal Talk to Children: A Longitudinal Study of Low-Income Families
}

\section{Citation}

Rowe, Meredith L., Barbara Alexander Pan, and Catherine Ayoub. 2005. “Predictors of Variation in Maternal Talk to Children: A Longitudinal Study of Low-Income Families." Parenting 5 (3): 259-283.

\section{Published Version}

doi:10.1207/s15327922par0503_3

\section{Permanent link}

http://nrs.harvard.edu/urn-3:HUL.InstRepos:13041212

\section{Terms of Use}

This article was downloaded from Harvard University's DASH repository, and is made available under the terms and conditions applicable to Other Posted Material, as set forth at http:// nrs.harvard.edu/urn-3:HUL.InstRepos:dash.current.terms-of-use\#LAA

\section{Share Your Story}

The Harvard community has made this article openly available.

Please share how this access benefits you. Submit a story.

\section{Accessibility}




\title{
Predictors of Variation in Maternal Talk to Children: A Longitudinal Study of Low-Income Families
}

\author{
Meredith L. Rowe, Barbara Alexander Pan, \\ and Catherine Ayoub
}

\begin{abstract}
SYNOPSIS
Objective. The goals of this study were (1) to examine the extent of variation in amount and lexical diversity of maternal talk to young children within a sample of low-income families, (2) to determine the patterns of change over time in maternal talk during the early childhood years, and (3) to consider specific predictors of variation in maternal communicative input. Design. Low-income mother - child dyads $(n=108)$ were videotaped at child ages 14,24 , and 36 months during semistructured play in the home. Videotapes were transcribed and analyzed using the conventions of the Child Language Data Exchange System to determine amount (word tokens) and lexical diversity (word types) of maternal talk to children. Background information collected from mothers at study entry served as predictors of variation in communicative input. Individual growth modeling methods were used to analyze data. Results. Mothers varied greatly in the number of tokens and types produced during interaction. Mothers were found to increase in their total amount of talk and diversity of vocabulary as children aged. In addition to child age, maternal education, language and literacy skills, depression, and age helped explain variation in level of maternal talk, but none of the predictors explained variation in growth. Different combinations of predictors explained variation in tokens versus types. Conclusions. Findings highlight the importance of studying specific predictors of parental talk to children, as even in low-income samples large variation in communicative input is evident.
\end{abstract}

\section{INTRODUCTION}

Variability in maternal communicative input to infants and toddlers is of considerable theoretical and applied interest, given its demonstrated value in predicting children's rates of development and later skill levels. In the domain of vocabulary development, both amount of maternal talk and diversity of lexical input addressed to children have been identified as predictors of vocabulary growth in children from low-income (Weizman \& 
Snow, 2001) and middle-class families (Bornstein, Tamis-LeMonda, \& Haynes, 1999; Hampson \& Nelson, 1993; Hoff, 2003; Hoff \& Naigles, 2002; Huttenlocher, Haight, Bryk, Seltzer, \& Lyons, 1991). The research literature on maternal input to infants and toddlers, based largely on examination of Western middle-class families, has identified both maternal and child characteristics as sources underlying the considerable variability observable in amount, lexical diversity, and pragmatic characteristics of speech directed to young children.

On the maternal side, factors such as socioeconomic class (Hart \& Risley, 1995; Hoff, Laursen, \& Tardif, 2002; Lawrence \& Shipley, 1996; Ninio, 1980), maternal level of education (Hoff-Ginsberg, 1992), age (Culp, Osofsky, \& O'Brien, 1996), verbal facility (Bornstein, Haynes, \& Painter, 1998) and mental health (Breznitz \& Sherman, 1987; Lovejoy, Graczyk, O'Hare, \& Newman, 2000) are reportedly associated with richer, more responsive, and more abundant talk to infants and toddlers. For example, Ninio (1980) reported that mothers with higher socioeconomic status produced more varied labels than did mothers with lower socioeconomic status in reading picture books with their infants. Hart and Risley (1995) later found that infants and toddlers in the professional families they studied heard several times as much talk at home as children in welfare-eligible families. Similarly, observing dyads in a laboratory setting, Lawrence and Shipley (1996) found that middle-class mothers provided more information and more object labels to their preschoolers than did working-class mothers.

Components of socioeconomic status, such as maternal education, are found to relate to maternal talk with young children. Hoff-Ginsberg (1992) showed that college-educated mothers produced more talk, more conversational-eliciting talk, and less directive talk in interaction with their toddlers than did high school-educated mothers. Borduin and Henggeler (1981), measuring maternal verbal ability directly, found verbal facility was a better predictor than socioeconomic status of maternal use of questions and commands. Likewise, cross-sectional studies with middle- and upper-middle-class families showed that maternal language and literacy skills predict maternal vocabulary use in interaction with children (e.g., Bornstein et al., 1998).

Previous research has also suggested the importance of considering socioemotional factors when studying mothers' communication with children. For example, Breznitz and Sherman (1987) found that mothers experiencing higher levels of depression talk less to their children. Bettes (1988) later found that depressed mothers are less responsive to infant vocalizations and are less likely to adopt intonational characteristics of child-directed speech in verbal interaction with their infants. Lower levels of vocalization in mother - child interaction have also been shown for more 
depressed mothers in a number of other studies (see meta-analysis by Lovejoy et al., 2000). To our knowledge, none of these studies examined lexical aspects of language (e.g., richness of vocabulary) that depressed mothers use in conversation with their young children. Finally, the role of mental health in maternal communicative input is particularly worthy of study in low-income, rural samples where depression is prevalent (Belle, 1990).

In addition to maternal characteristics, stable child characteristics such as birth order and gender have been implicated as sources of variation in input. Some but not all studies report more abundant and richer input to firstborn children (Jones \& Adamson, 1987; Hoff-Ginsberg, 1998; McCartney, Robeson, Jordan, \& Mouradian, 1991), and mothers have been found to talk more to daughters than sons in some studies (Leaper, Anderson, \& Sanders, 1998; cf. Rowe, Coker, \& Pan, 2004). More consistent findings emerge when time-varying characteristics, such as the child's age, language abilities, and/or verbal production, are examined. A large body of work on child-directed speech has shown that certain features of adult speech vary as a function of child age and language abilities (e.g., Bellinger, 1980; Cross, 1977; Snow, 1972). In a more recent cross-sectional analysis, Hoff-Ginsberg (1994) showed that mothers talked more to toddlers who more often continued the maternal topic of conversation, indicating that children who are good turn-takers or who have better conversational skills elicit more maternal verbal input.

In contrast to this rich body of research literature describing variability in maternal input to children in middle-class and, to a lesser extent, working-class families, information about verbal interaction between mothers and children in low-income families is extremely limited. Until quite recently, Hart and Risley's (1995) detailed study of 6 welfare-eligible families and their children, followed through child age 3, and the Home School Study of Language and Literacy Development (DeTemple \& Snow, 1996; Dickinson \& Tabors, 2001) of 74 families beginning when children were preschoolers, represented the bulk of longitudinal work on spontaneous parent-child verbal interaction in low-income families. A number of other studies were either cross-sectional in design and/or involved very small samples (e.g., Barnes, Gutfreund, Satterly, \& Wells, 1983; Pan \& Rowe, 1999), or were based only on observer ratings of mother - child verbal interaction (Roberts, Burchinal, \& Durham, 1999).

Given the paucity of research focused on low-income samples, the field of child language research is left with a number of as yet unanswered questions about variability in maternal input to children in low-income families. Many studies have shown socioeconomic effects across social classes, yet few have reported on sources of variation among low-income mothers. 
In this article, we make a modest effort to address this gap in the literature by analyzing longitudinal data from 108 low-income families with children aged 14 to 36 months. Recent work with this sample has shown that diversity of maternal lexical input (word types), rather than maternal talkativeness (word tokens), predicted growth in children's vocabulary production in toddlerhood (Pan, Rowe, Singer, \& Snow, in press), leading us to question whether different maternal characteristics might predict variation across mothers in these two features of input. We anticipated that individual mothers would increase in both the lexical diversity and amount of talk they addressed to their children as the children matured and improved in language ability. Furthermore, we expected, based on the previously reviewed literature, that different maternal characteristics would predict variation in lexical diversity and talkativeness. For example, mental health may relate more to quantity of talk rather than diversity of vocabulary, and maternal literacy skills may relate more to vocabulary use than to quantity of talk. So as to compare our work to previous research with more advantaged families, we focused our investigation on key factors (e.g., education, verbal facility, mental health) identified in the literature as predictive of variability in verbal input of middle- and working-class mothers. Focusing on these maternal characteristics offered the additional advantage that they would be potentially amenable to intervention. The specific research questions addressed in this study were: (1) How much variability is there in amount and lexical diversity of maternal talk directed to children within this sample of low-income families? (2) What are the patterns of change over time in maternal verbal input directed to children between 14 and 36 months? and (3) Do maternal characteristics such as education, language and literacy skills, and depression account for variation in level and/or growth of maternal lexical diversity and amount of talk addressed to children, controlling for key child and family background variables?

\section{METHODS}

\section{Participants}

Study participants were drawn from a larger sample of 146 mother child dyads participating in a national longitudinal study on the effectiveness of Early Head Start (EHS; U.S. Department of Health and Human Services, Administration for Children and Families, 2001). At entry to the study, families were living in southern Vermont and qualified for EHS. Families enrolled during the mother's pregnancy or before the target 
child's first birthday. The number of children in the family was not a selection criterion. Families were not allowed to participate if they had any child enrolled in one of several other intervention programs in the previous 5 years, or if they had been enrolled in any federal, state, or local program with similar services in the previous 12 months. Recruitment procedures included posting flyers, going door to door, and contacting other service providers in the area. Families were continuously recruited during the 27-month recruitment period, resulting in a sample of increasing size over time. The EHS program being studied in Vermont exhausted recruitment capabilities and was confident that the 146 families found were all the eligible families in the county during the allowed period of recruitment. Parents were predominantly European American (91\%) and used English as their home language (99\%). Families were randomly assigned on entry to the study to either the program or comparison group. All data examined in this study were collected on both program and comparison families.

The 119 families originally chosen for this study were those who agreed to be videotaped on at least one of three occasions. One was excluded because English was not the primary language in the home, and therefore the target child was not a native English speaker. Three additional families were excluded because the custody of the child changed from one time point to the next. Data from one family at 36 months only, but not at the earlier ages, was excluded because the filming conditions did not meet project standards, and 7 additional families were excluded due to incomplete data collection on necessary measures other than the videotaped interaction. Therefore, the final sample size was 108 families.

Of these 108 families, data are available for 57 dyads at all three waves, 27 dyads at two waves, and 24 dyads at one wave. One of the advantages of using individual growth modeling was that all 108 dyads could be included in the analysis (Singer \& Willett, 2003). Although those with fewer than three waves provided less, or no, information about within-person variation - and hence did not contribute to the estimation of variance components - they did contribute to the estimation of fixed effects (the structural portion of the individual growth model). We conducted several analyses to determine whether missingness was related to background characteristics of families. Specifically, we compared mothers' education, age, literacy skills, level of depression, family income, and EHS program status across the groups with one, two, and three waves of data available. There were no significant differences between any groups on any of these measures.

EHS is a child development program for low-income families. Thus, family income is a key selection criterion. However, the requirement that 
$10 \%$ of enrollment opportunities be available to children with disabilities sometimes results in enrollment of families with incomes above federal poverty guidelines. In this sample the average yearly family income (as reported by the mother at baseline) was $\$ 11,237(S D=\$ 7,778)$ with a median of $\$ 9,240$ and a range from $\$ 0$ to $\$ 40,664$. Seventy-five percent of the families reported incomes of $\$ 14,000$ or less, and $10 \%$ of the families reported incomes of $\$ 24,000$ or more. The average maternal age at baseline was 25.5 years $(S D=6.5$ years $)$. Forty-eight percent of the children were firstborn, and $50 \%$ were male. Fifty-one percent of the sample had been randomly assigned to the EHS program group.

\section{Procedure}

Data collection in the larger EHS study included child assessments, maternal interviews, home and family observations, and childcare observations for children in out-of-home care at least $10 \mathrm{hr}$ per week. The results presented here are based on background demographic information and questionnaire data collected at baseline (study entry) and spontaneous speech samples from videotaped mother - child interaction collected at up to three time points. Child ages varied somewhat around the anticipated 14-, 24-, and 36-month marks, with an age range of approximately 4 months at Wave 1, 10 months at Wave 2, and 5 months at Wave 3 . Descriptive statistics for child age at each wave are presented in Table 1 . To control for this variation, child age (in months) was used as the measure of time in growth models.

At each home visit dyads were provided with three bags containing a book and various toys. At 14 months, a wordless book was provided, Good Dog Carl by Alexandra Day; at 24 and 36 months it was The Very Hungry Caterpillar by Eric Carle. At all three time points, age-appropriate toys were intended to facilitate talk and pretend play (e.g., a toy cooking set, an ark with animals). This procedure is similar to that used by Vandell (1979) and others (e.g., National Institute of Child Health and Human Development Early Child Care Research Network [NICHD], 2000; Snow, Pan, ImbensBailey, \& Herman, 1996). Mothers were asked to start with the bag containing the book, then move on to the other two bags in turn. Dyads were not required to play with all the toys and could spend as much or little time on any one bag as they liked during the 10 -min period. The pace and transition from one toy to the next was determined by mother and child.

The sampling approach adopted here of 10-min mother - child interaction has been used by a number of other researchers studying both children's vocabulary production and maternal input in families with infants and toddlers (e.g., Bornstein et al., 1998; Corkum \& Dunham, 1996; Pan, 
TABLE 1

Descriptive Statistics

\begin{tabular}{|c|c|c|c|c|}
\hline & M & $S D$ & Min & $\operatorname{Max}$ \\
\hline \multicolumn{5}{|l|}{ Child age at each wave (in months) } \\
\hline Wave $1(n=98)$ & 14.7 & 1.0 & 13.1 & 16.9 \\
\hline Wave $2(n=82)$ & 25.0 & 1.7 & 22.7 & 32.4 \\
\hline Wave $3(n=69)$ & 36.8 & 1.4 & 34.9 & 39.9 \\
\hline \multicolumn{5}{|l|}{ Outcome measures } \\
\hline \multicolumn{5}{|c|}{ Mother tokens (in 10-min of mother - child interaction) } \\
\hline Wave 1 (child age ca. 14 months) & 505.3 & 259.2 & 49 & 1244 \\
\hline Wave 2 (child age ca. 24 months) & 629.3 & 234.1 & 163 & 1294 \\
\hline Wave 3 (child age ca. 36 months) & 638.3 & 220.7 & 197 & 1236 \\
\hline \multicolumn{5}{|c|}{ Mother types (in 10-min of mother - child interaction) } \\
\hline Wave 1 (child age ca. 14 months) & 124.6 & 42.5 & 29 & 221 \\
\hline Wave 2 (child age ca. 24 months) & 164.0 & 45.7 & 74 & 320 \\
\hline Wave 3 (child age ca. 36 months) & 187.8 & 49.9 & 94 & 334 \\
\hline \multicolumn{5}{|l|}{ Predictor measures } \\
\hline Maternal education (in years) & 11.8 & 1.4 & 8 & 18 \\
\hline Vocabulary IQ ${ }^{\mathrm{a}}$ & 36.7 & 13.3 & 12 & 66 \\
\hline Literacy ${ }^{b}$ & 50.6 & 5.2 & 28 & 57 \\
\hline Depression $^{\mathrm{C}}$ & 20.3 & 10.9 & 4 & 55 \\
\hline
\end{tabular}

a Vocabulary IQ was measured using the Wechsler Adult Intelligence Scale vocabulary subscale raw scores.

bLiteracy was measured using the Woodcock-Johnson Tests of Achievement letter-word identification task raw scores.

cDepression was measured using the Center for Epidemiological Studies-Depression scale raw scores.

Rowe, Spier \& Tamis-LeMonda, 2004). Although relatively brief, such observations demonstrate wide variability across mothers and allow sampling of a larger number of families than is possible in ethnographic work. Furthermore, summary measures such as word types and word tokens are less sensitive to length of observation than are more specific, rare linguistic constructions (Tomasello \& Stahl, 2004).

\section{Transcription and Measures}

Videotaped mother - child interactions were transcribed using the Codes for the Human Analysis of Transcripts (CHAT) conventions of the Child Language Data Exchange System (CHILDES; MacWhinney, 2000). The unit of transcription was the verbal utterance or nonverbal action/gesture, defined as any statement or action/gesture by one speaker bounded by grammatical closure and/or a pause of more than 2 sec or transition in speaker. A second transcriber verified all transcripts to ensure that all speech was transcribed 
accurately. Automated analyses of the transcripts provided information on the number of words mothers produced (word tokens) and the diversity of vocabulary used (word types). Words that were produced in imitation or repetition of the child were considered part of the corpus of mother-produced words. All words that the mother produced, whether dictionary words, proper names, or meaningful sound effects (e.g., oops) were included in the corpus of tokens and types. No attempt was made to filter out interactional markers (e.g., uh uh, indicating disagreement) or fillers (e.g., $u m$, vocalized pause), although frequency lists of words in each transcript were examined to ensure that word counts were not artificially inflated due to inconsistencies in spelling/transcription (e.g., oops and woops were always transcribed as oops). Several decisions were made as to what constituted a word type. Morphologically inflected variants of a given word (e.g., bike and bikes) were considered a single type, but alternate forms of words (e.g. bike and bicycle) were considered two word types. Assimilations and contractions such as gonna and I'll were considered equivalent to their full forms (e.g., going to and I will) for purposes of counting both types and tokens. Thus, gonna and I'll each consisted of two word types (go and to, I and will), and each constituted two tokens.

The two separate measures, tokens and types, served as outcome variables. At each data collection wave (14, 24, and 36 months), the association between mother tokens and mother types was quite strong, $r \mathrm{~s}(96,80,68)=$ $.86-.90$, indicating that mothers who talked more used more diverse vocabulary than mothers who talked less. In this study we considered maternal tokens and types as separate input variables because, due to their differing effects on child vocabulary development (Pan, et al., in press), we were interested in whether similar or different factors relate to variation in maternal tokens and types.

Maternal education level was collected at baseline, measured in years. Education was centered at 12 by subtracting 12 years from each observed value, thus allowing us to interpret the fitted intercepts of our models as representing an individual with 12 years of education, approximately the sample mean (Singer \& Willett, 2003).

The vocabulary subscale of the Wechsler Adult Intelligence Scale-Revised (WAIS-R; Wechsler, 1981) and the letter - word identification portion of the Woodcock - Johnson Tests of Achievement (WJ; Woodcock, 1978) were administered to mothers at baseline. As expected, maternal vocabulary (WAIS) and literacy (WJ) measures were related to one another, $r(106)$ $=.55, p<.001$. To reduce the number of predictors in our statistical models, these measures were standardized and combined, using principal components analysis. We chose to use the first principal component, which weighted the variables equally and explained $77 \%$ of the total variance in 
the original two variables, as our measure of the construct "language and literacy skills."

The Center for Epidemiologic Studies - Depression (CES-D; Radloff, 1977) scale, on which adults rate on a 4-point scale the frequency with which they have recently experienced 20 depressive symptoms, was administered to mothers at baseline and at child ages 14, 24, and 36 months. The average mother in this sample was mildly depressed at baseline, although the distribution of scores was positively skewed. On average, there was no change over time in maternal depression levels. Because exploratory analysis in this study suggested that the linearity assumption of the individual growth models was better met if the CES-D scores were transformed, the analyses presented in this paper use the logarithm (to base 2) of the mother's CES-D scores at baseline. Baseline scores were chosen due to the least amount of missing data. Scores were inputed for 24 mothers using regression estimates from models using the same mothers' Child Abuse Potential and depression subscale of the Parenting Stress Index scores, also given at baseline and positively associated with CES-D.

Child gender, child birth order, maternal age, family income (in log base 2 transformation form due to the skewed distribution), and participation in the EHS study served as control variables, based on previous literature highlighting their importance. The transformed income variable was not related to education in this sample; therefore, both measures were used in the analyses, education as a predictor and income as a control. EHS program versus comparison group status was included as a control predictor due to study design.

\section{RESULTS}

\section{Descriptive Statistics}

As presented in Table 1, there is large variation observed among mothers in the number of tokens and types produced during 10-min interactions with their children. For example, at child age 24 months the mean number of maternal tokens produced in 10 min was 629, and there was a large standard deviation in relation to the mean of 234 . Thus, some mothers produced more than 1,200 word tokens during the dyadic interaction, whereas others produced fewer than 200. This variation was evident in both tokens and types and at all time points and suggested that investigation of predictors of variation in maternal verbal communicative input within this low-income sample was warranted. Furthermore, the mean 
values of maternal tokens and types increased over time between the child's first and third birthdays.

Developing a Multilevel Model of Growth in Maternal Tokens and Types

We used individual growth modeling techniques to further analyze these longitudinal data. The multilevel model for change allowed us to simultaneously address two research questions: a level-1 question focused on individual change over time in maternal talk (within-person change), and a level-2 question concerned how this change varied across individuals (between-person change; Singer \& Willett, 2003). To develop an appropriate level-1 model to describe the growth rates in maternal tokens and types, we examined the empirical growth trajectories for all mothers and fit a series of baseline growth models comparing different parameterizations of time. In particular we fit models using linear, quadratic, linear and quadratic, and log versions of time, where time was measured as child age in months. All analyses were conducted using SAS PROC MIXED, Full Maximum Likelihood method. Preliminary results indicated that a linear model was most appropriate for the Mother Tokens data, and a log base 2 transformation of child age best fit the Mother Types data. For ease of presentation and interpretation, we aimed to adopt one common model specification for both outcome measures. The best fitting level-1 specification was a linear model resulting in the following equations:

$$
\begin{gathered}
\text { MOTHER TOKENS } i t=\pi_{0 i}+\pi_{1 i}(\text { Age-24) })_{i t}+\varepsilon_{i t} \\
\text { MOTHER TYPES } i t=\pi_{0 i}+\pi_{1 i}(\text { Age }-24)_{i t}+\varepsilon_{i t}
\end{gathered}
$$

In Equation 1, MOTHER TOKENS it and MOTHER TYPES $S_{i t}$ represent the number of tokens or types produced for mother $i$ at time $t$ months. Because child age was centered around 24 months, the individual growth parameters have the following interpretations: $\pi_{0 i}$ represents the intercept, or mother $i$ 's true level of tokens or types production at child age 24 months, and $\pi_{1 i}$, represents mother $i$ 's linear acceleration in growth over time. Finally, the residuals $\varepsilon_{t i}$ represent the proportion of mother $i$ 's tokens or types produced at age $t$ that is not predicted by her child's age.

The between-person portion of the multilevel model for change (level-2) used the initial status and growth parameters from the within-person (level-1) models as outcomes, and enabled us to determine whether there was variation in initial status or rates of change in token or type use across mothers. We then used our predictors to try and explain some of this 
interindividual variation. The simplest level-2 specifications were unconditional growth models, in which we included no substantive predictors and instead allowed each level-1 predictor to vary randomly around its population mean.

$$
\begin{aligned}
& \pi_{0 i}=\beta_{00}+u_{0 i} \\
& \pi_{1 i}=\beta_{10}+u_{1 i}
\end{aligned}
$$

Conceptually, each submodel in Equation 2 treats the level-1 growth parameters as outcomes. The two fixed effects $\left(\beta_{00}, \beta_{10}\right)$ served as level-2 "intercepts," and thus represent the average true level or initial status of token and type production at 24 months, as well as the average true instantaneous rate of change over time or slope. The level-2 residuals $\left(u_{0 i}, u_{1 i}\right)$ represent the deviation of each mother's estimated initial status and growth parameters from the population average. The variance components (variances and covariance) of the level-2 models are termed random effects. The variances $\tau_{00}$ and $\tau_{11}$ represent the variance in intercepts and rates of change in the population, controlling for child age. The covariance $\tau_{01}$ represents the relation between intercept and linear growth. Having specified these unconditional level-2 models, it was relatively straightforward to add substantive person-level predictors to the right-hand sides of these equations to allow us to assess whether maternal and child characteristics were associated with variation in the individual growth parameters.

\section{An Unconditional Growth Model}

Table 2 presents the results of initial model building. The first models we fit were unconditional means models, followed by unconditional growth models presented in Equations 1 and 2 for both outcome measures (maternal tokens and types). Unconditional means models are models with no predictors and primarily serve as a baseline for model comparison. The unconditional growth models, or models including only linear time (in this case child age) as a predictor, were fit next to try to reduce the amount of within-person variance found in the means models and to obtain parameter estimates for level and change over time in maternal input. As expected, the inclusion of child age in the unconditional growth models reduced the estimated within-person variance allowing the goodness-of-fit statistics (-2LL and AIC) to suggest better fit (Table 2). We calculated pseudo- $R^{2}$ statistics, or proportional reduction in variance, to determine how much of the systematic level-1 variance was explained by child age. Results indicated that $40 \%$ of the systematic within-person variation in use of maternal tokens was explained by child age, compared to $68 \%$ of 
TABLE 2

Unconditional Means and Growth Models for Maternal Tokens and Types

\begin{tabular}{|c|c|c|c|c|}
\hline & \multicolumn{4}{|c|}{ Variance Estimates (Standard Error) } \\
\hline & \multicolumn{2}{|c|}{ Mother Tokens } & \multicolumn{2}{|c|}{ Mother Types } \\
\hline & $\begin{array}{l}\text { Means } \\
\text { Model }\end{array}$ & $\begin{array}{c}\text { Growth } \\
\text { Model }\end{array}$ & $\begin{array}{l}\text { Means } \\
\text { Model }\end{array}$ & $\begin{array}{c}\text { Growth } \\
\text { Model }\end{array}$ \\
\hline \multicolumn{5}{|l|}{ Fixed effects: } \\
\hline Intercept & $\begin{array}{l}573.70^{* * *} \\
(21.08)\end{array}$ & $\begin{array}{l}575.89^{* * *} \\
(20.71)\end{array}$ & $\begin{array}{c}152.97^{* * *} \\
(4.08)\end{array}$ & $\begin{array}{c}152.92^{* * *} \\
(3.81)\end{array}$ \\
\hline Child age & & $\begin{array}{l}6.01^{* * *} \\
(1.17)\end{array}$ & & $\begin{array}{l}2.82^{* * *} \\
(0.26)\end{array}$ \\
\hline \multicolumn{5}{|l|}{ Random effects: } \\
\hline Level-1: Within-person & $\begin{array}{l}23716^{* * *} \\
(2786)\end{array}$ & $\begin{array}{l}14345^{* * *} \\
(2338)\end{array}$ & $\begin{array}{l}1751.9^{* * *} \\
(204.74)\end{array}$ & $\begin{array}{c}554.9^{* * *} \\
(92.34)\end{array}$ \\
\hline Level-2: Status/level at 24 months & $\begin{array}{l}36307^{* * *} \\
(6521)\end{array}$ & $\begin{array}{l}38418^{* * * *} \\
(6212)\end{array}$ & $\begin{array}{l}973.86^{* * *} \\
(248.34)\end{array}$ & $\begin{array}{l}1231.9^{* * * *} \\
(206.56)\end{array}$ \\
\hline Linear Slope & & $\begin{array}{c}47.82^{* *} \\
(19.78)\end{array}$ & & $\begin{array}{l}2.95^{* * *} \\
(0.92)\end{array}$ \\
\hline Covariance & & $\begin{array}{c}-515.64^{*} \\
(236.17)\end{array}$ & & $\begin{array}{c}6.92 \\
(9.29)\end{array}$ \\
\hline \multicolumn{5}{|l|}{ Goodness of fit: } \\
\hline$-2 \mathrm{LL}$ & 3373.3 & 3337.2 & 2653.0 & 2531.1 \\
\hline $\mathrm{AIC}$ & 3379.3 & 3349.2 & 2659.0 & 2543.1 \\
\hline
\end{tabular}

${ }^{*} p<.05 .{ }^{* *} p<.01{ }^{* * *} p<.001$.

the variation in maternal types. Therefore, child age explained some of the variation over time in use of tokens and types for each mother, but some variation remained to be explained by other predictors.

The intercept estimates of the unconditional growth models were very similar to the average estimates in our unconditional means models due to the fact that our data were centered at child age 24 months, approximately the mean child age. The significant positive parameter estimates for linear growth (child age) in the maternal tokens and types models indicated that mothers did increase over time in their use of tokens and types between child age 14 and 36 months, $p<.001$. The parameter estimates for the fixed effects in the unconditional growth model predicting maternal tokens indicated that mothers produced, on average, approximately 576 word tokens per 10 min at child age 24 months, and in the 2 years under study increased at a rate of 6 word tokens per month. The parameter estimates for the fixed effects in the unconditional growth model predicting maternal types showed that mothers produced, on average, approximately 153 word types at child age 24 months, and increased at a linear rate of 2.8 word 
types per month in the 2-year period under study. The average fitted growth trajectories for maternal tokens and types based on these unconditional growth models are presented in Figure 1.

Predicting Maternal Communicative Input:

The Role of Predictor and Control Variables

Our predictor variables fell into two categories: (1) priority predictors including maternal education, language and literacy skills, and depression, and (2) controls including child gender, child birth order, maternal age, family income, and EHS program status. Table 3 presents the final results of the hierarchical model-fitting process showing the effects of the priority predictors and controls on maternal tokens and types respectively. Models 1a and 2a showed the effect of priority predictors, and Models $1 \mathrm{~b}$ and $2 \mathrm{~b}$ are the final models including significant controls.

Model 1a (see Table 3) showed that maternal education had a significant positive effect on the level of maternal word tokens, $p<.001$, controlling for maternal depression. In addition, controlling for maternal education, ma-

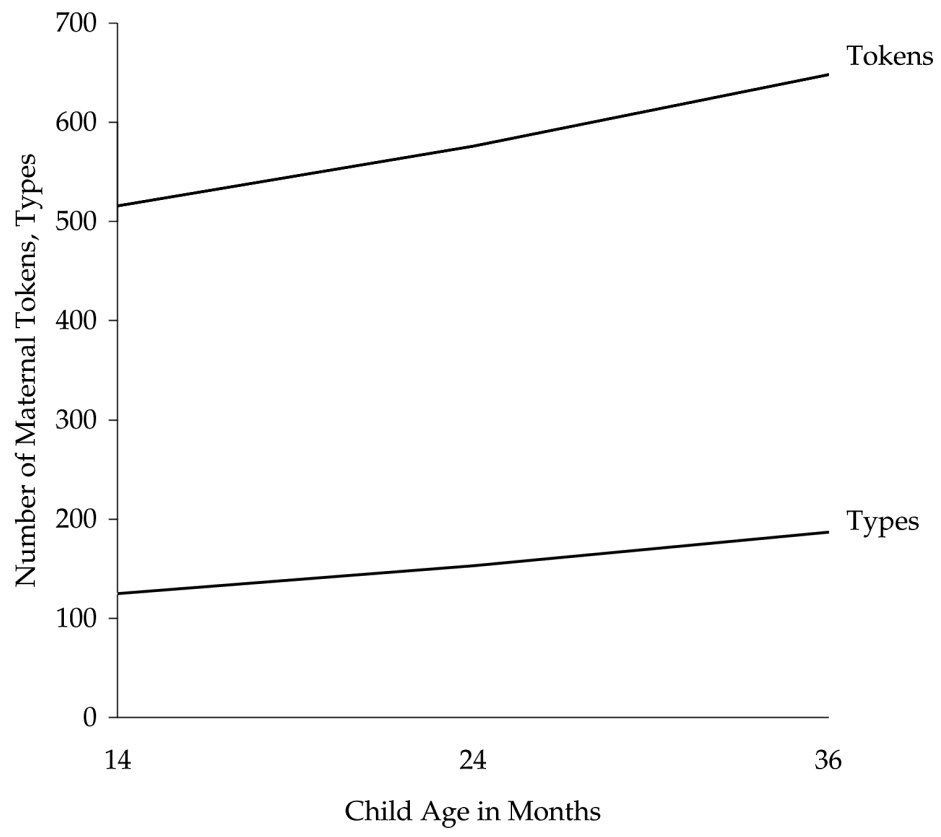

FIGURE 1

Average Growth in Maternal Tokens and Types (per $10 \mathrm{~min}$ ) Between Child Age 14 and 36 Months $(n=108)$. 
TABLE 3

Estimates of Fixed and Random Effects from a Series of Individual Growth Models in Which Maternal Education, Language and Literacy Skils, Depression, and Age Predict Level and Linear Rate of Change in Maternal Use of Word Tokens and Types Between Child Age 14 and 36 Months

\begin{tabular}{|c|c|c|c|c|}
\hline & \multicolumn{4}{|c|}{ Parameter Estimates (Standard Error) } \\
\hline & \multicolumn{2}{|c|}{ Mother Tokens } & \multicolumn{2}{|c|}{ Mother Types } \\
\hline & Model 1a & Model 1b & Model 2a & Model 2b \\
\hline \multicolumn{5}{|l|}{ Fixed effects: } \\
\hline Intercept & $\begin{array}{l}804.89^{* * *} \\
(97.50)\end{array}$ & $\begin{array}{l}493.53^{* * *} \\
(120.62)\end{array}$ & $\begin{array}{c}154.79^{* * *} \\
(3.35)\end{array}$ & $\begin{array}{l}111.00^{* * *} \\
(14.05)\end{array}$ \\
\hline Child age & $\begin{array}{l}6.22^{* * *} \\
(1.17)\end{array}$ & $\begin{array}{l}6.22^{* * *} \\
(1.16)\end{array}$ & $\begin{array}{l}2.90^{* * *} \\
(0.26)\end{array}$ & $\begin{array}{l}2.91^{* * *} \\
(0.26)\end{array}$ \\
\hline Education & $\begin{array}{l}56.30^{* * *} \\
(12.79)\end{array}$ & $\begin{array}{l}36.12^{* *} \\
(12.97)\end{array}$ & $\begin{array}{l}10.06^{* * *} \\
(2.55)\end{array}$ & $\begin{array}{l}7.08^{* *} \\
(2.60)\end{array}$ \\
\hline Language/literacy skills & & & $\begin{array}{c}6.30^{*} \\
(2.89)\end{array}$ & $\begin{array}{c}5.93^{*} \\
(2.75)\end{array}$ \\
\hline Depression (log) & $\begin{array}{l}-52.86^{*} \\
(23.14)\end{array}$ & $\begin{array}{c}-47.35^{*} \\
(21.57)\end{array}$ & & \\
\hline Mother age & & $\begin{array}{l}11.21^{* * *} \\
(2.86)\end{array}$ & & $\begin{array}{l}1.71^{* *} \\
(0.53)\end{array}$ \\
\hline \multicolumn{5}{|l|}{ Random effects: } \\
\hline Level-1: Within-person & $\begin{array}{c}14346^{* * *} \\
(2331.3)\end{array}$ & $\begin{array}{c}14572 * * * \\
(2372.2)\end{array}$ & $\begin{array}{l}564.85^{* * *} \\
(94.70)\end{array}$ & $\begin{array}{l}571.47^{* * *} \\
(96.27)\end{array}$ \\
\hline Level-2: Status/level at 24-months & $\begin{array}{l}29842^{* * *} \\
(5071.4)\end{array}$ & $\begin{array}{c}24882^{* * *} \\
(4443.7)\end{array}$ & $\begin{array}{l}865.18^{* * *} \\
(161.85)\end{array}$ & $\begin{array}{l}751.87^{* * *} \\
(148.18)\end{array}$ \\
\hline Linear slope & $\begin{array}{c}49.15^{* *} \\
(19.84)\end{array}$ & $\begin{array}{c}47.89^{* *} \\
(19.72)\end{array}$ & $\begin{array}{l}2.95^{* * *} \\
(0.93)\end{array}$ & $\begin{array}{l}2.91^{* * *} \\
(0.93)\end{array}$ \\
\hline Covariance & $\begin{array}{l}-575.12^{* *} \\
(217.19)\end{array}$ & $\begin{array}{c}-533.70^{* *} \\
(201.97)\end{array}$ & $\begin{array}{c}1.02 \\
(8.26)\end{array}$ & $\begin{array}{l}-0.82 \\
(7.90)\end{array}$ \\
\hline \multicolumn{5}{|l|}{ Goodness of fit: } \\
\hline$-2 \mathrm{LL}$ & 3314.0 & 3299.8 & 2505.2 & 2495.5 \\
\hline AIC & 3330.0 & 3317.8 & 2521.2 & 2513.5 \\
\hline
\end{tabular}

Note. Only final models are presented. Other models are available upon request. ${ }^{*} p<.05 .{ }^{* *} p<.01 .{ }^{* * *} p<.001$.

ternal depression had a significant negative effect on the level of maternal word tokens, $p<.05$. There was no effect of maternal education or depression on change over time in maternal tokens, and no effect of maternal language and literacy skills on level or change over time in maternal tokens. Therefore, Model 1a, a model containing the main effects of maternal education, $p<.001$, and depression, $p<.05$, was the most parsimonious model we could fit to our data using the priority predictors to explain level and growth in maternal word tokens. 
Based on this model, we found that more educated mothers and less depressed mothers produced more word tokens in interaction with their children than did mothers with fewer years of schooling and higher levels of depression. More specifically, controlling for depression, for every additional year of schooling, the average number of maternal word tokens per 10 min increased by 56 tokens. And, controlling for years of schooling, for every doubling in score on the depression measure (log base 2), the average number of maternal word tokens per 10 min decreased by 53 tokens. We calculated a pseudo- $R^{2}$ statistic that quantified the proportional reduction of level-2 variance (Singer \& Willett, 2003) as a measure of the effect sizes of our predictors. Taken together, maternal education and depression explained $22 \%$ of the variation in initial status of maternal tokens when added to the model already including child age as the measure of time. We conclude that our primary predictors education and depression affect level of maternal use of word tokens, but they have no effect on change over time in use of maternal tokens.

Model 2a showed that maternal education had a significant positive effect on the level of maternal word types, $p<.001$, controlling for language and literacy skills. Furthermore, controlling for education, language and literacy skills had a significant positive effect on the level of diversity of maternal vocabulary, $p<.05$. There was no effect of maternal education or language and literacy on change over time in maternal types, and there was no effect of maternal depression on level or change over time in maternal types. Therefore, Model 2a, a model containing the main effects of maternal education, $p<.001$, and maternal language and literacy skills, $p<$ .05 , was the most parsimonious model we could fit to the data using our priority predictors to explain level and growth in maternal word types.

The association between scores on the language and literacy composite and maternal education was moderate, yet statistically significant, $r(106)=$ $.36, p<.001$, and based on Model $2 \mathrm{a}$, they were both positively related to maternal use of word types. More specifically, controlling for language and literacy skills, for every additional year of schooling, the average number of maternal word types per $10 \mathrm{~min}$ increased by 10 types. Furthermore, controlling for education, for every additional point on the language and literacy composite, the average number of maternal word types per $10 \mathrm{~min}$ increased by 6 types. Therefore, mothers with more schooling and higher language and literacy skills produced more word types during interaction with their toddlers than did mothers with less schooling and lower language and literacy skills. Taken together, maternal education and language and literacy skills explained $30 \%$ of the variation in initial status in maternal word types. There was no effect of education or language and literacy skills on change over time in use of maternal types. 
Our next step in the model building process was to investigate the effect of control variables: maternal age, family income, child gender, child birth order, and whether the family was in the EHS program or comparison group, controlling for significant priority predictors. These results are presented for maternal tokens and types in Models $1 b$ and $2 b$, respectively (Table 3). Neither child gender, birth order, program status, nor family income significantly predicted level or growth in maternal tokens or types, controlling for significant priority predictors. However, maternal age was a significant predictor of level of both maternal tokens and types when added to the models containing significant priority predictors. In each case the inclusion of maternal age in the models reduced the strength of the maternal education effect, yet it remained significant. Maternal age explained an additional $13 \%$ of the variation in initial status of maternal tokens, and an additional $9 \%$ of the variation in initial status of maternal types. There was no effect of maternal age on growth in tokens or types. The final model for maternal tokens (Model 1b) contained the main effects of education, $p<$ .01 ; depression, $p<.05$; and maternal age, $p<.001$; and these predictors combined to explain approximately $35 \%$ of the variation in initial status. The final model for maternal types (Model 2b) contained the main effects of education, $p<.01$; language and literacy skills, $p<.05$; and maternal age, $p<.01$; and these predictors combined to explain approximately $39 \%$ of the variation in initial status. The significant variance components associated with the final models (the random effects in Table 3) indicate that there is remaining unpredicted variation in both initial status or level and rates of change to be explained by other predictors. The level- 1 and level- 2 residuals from both final models were examined to ensure that the homoscedasticity assumption was not violated. In all cases residuals were normally distributed, meeting model requirements. In sum, all predictors in the final models had significant effects on level of maternal tokens or types, but not on growth over time in their use. Thus, the predictors were useful in explaining variation in the intercept, but not in slope.

The final models for mother tokens and mother types are illustrated in Figures 2 and 3, respectively. In these figures we plot the estimated number of tokens and types produced for four prototypical groups of mothers to highlight the effects of significant predictors. All lines in each figure are parallel because none of our predictors had an effect on growth. One finding that these figures highlight is the strong effect of maternal age. For example, in Figure 2 we see that older, more educated mothers with low levels of depression produced an estimated 140 more word tokens per $10 \mathrm{~min}$ than did younger mothers with the same levels of education and depression (Figure 2: comparing the solid lines). Similarly, Figure 3 shows that 


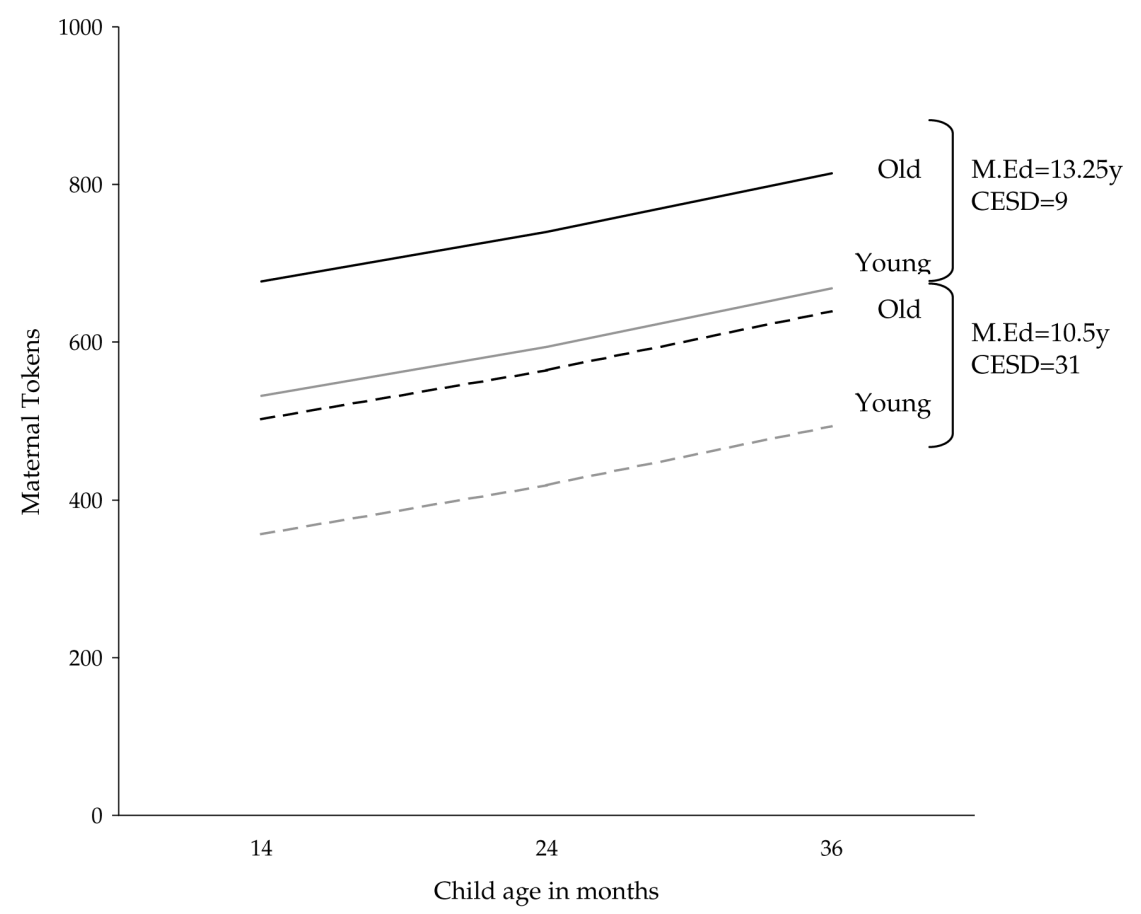

FIGURE 2

Effect of Maternal Education, Depression, and Age on Maternal Use of Word Tokens ( $n$ $=108$ ). One standard deviation above and below the mean for each variable was used. Maternal education is represented as 13.25 versus 10.5 years; CES-D scores as 31 (more depressed) and 9 (less depressed); Old $=32$ years, Young $=19$ years. The top two lines represent the estimated number of tokens produced by old and young mothers with 13.25 years of education and low CES-D scores of 9. The bottom two lines represent the estimated number of tokens produced by old and young mothers with 10.5 years of education and high CES-D scores of 31 .

older mothers with more education and language and literacy skills produced an estimated 22 more word types per $10 \mathrm{~min}$ than did younger mothers with the same levels of education and language and literacy skills (Figure 3: comparing the solid lines). Furthermore, despite age, mothers with more schooling and fewer depressive symptoms produced more word tokens in interaction with their toddlers than did mothers with less schooling and more depressive symptoms (Figure 2), and mothers with more schooling and language and literacy skills produced more word types with their toddlers than did mothers with less schooling and lower language and literacy skills (Figure 3). 


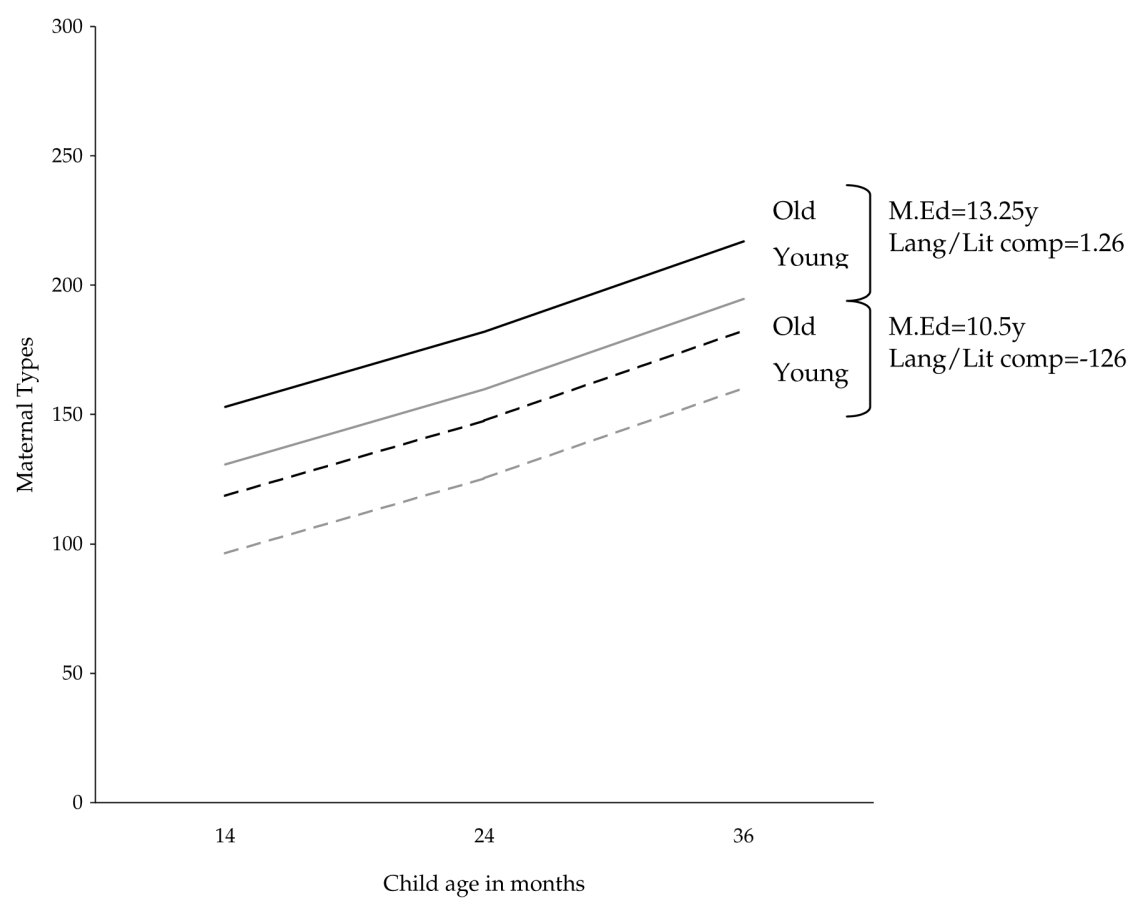

FIGURE 3

Effect of Maternal Education, Language and Literacy, and Age on Maternal Use of Word Types $(n=108)$. One standard deviation above and below the mean for each variable was used. Maternal education is represented as 13.25 versus 10.5 years; scores of 1.26 versus -1.26 on the language/literacy composite reflect high and low scores; Old $=32$ years, Young $=19$ years. The top two lines represent the estimated number of types produced by old and young mothers with 13.25 years of education and high language and literacy scores (1.26 composite). The bottom two lines represent the estimated number of types produced by old and young mothers with 10.5 years of education and low scores on the language and literacy composite (-1.26).

\section{DISCUSSION}

This longitudinal study of maternal talk to children in low-income families was designed to investigate (1) the extent of variation in amount and lexical diversity of maternal talk to young children within a low-income sample, (2) the patterns of change over time in maternal talk during the early childhood years, and (3) whether specific predictors might explain variation in maternal communicative input. In short, mothers varied greatly in the number of word tokens and types produced during interaction, and they increased in their total amount of talk and diversity of vocabulary as 
children aged. Maternal education, depression, and age predicted variation in level of maternal tokens, and maternal education, language and literacy skills, and age explained variation in level of maternal types. None of the predictors examined explained variation in change over time in maternal communicative input.

\section{Variation in Communicative Input}

This study documented large variation in the amount and lexical diversity of maternal talk during mother - child interaction in low-income families. For example, in this sample the child with the most talkative mother heard 25 times as many word tokens in 10 min of interaction than did the child with the least talkative mother. Building on Hart and Risley's (1995) findings based on 6 families, the results of this study of 108 families adds to a growing body of literature documenting considerable variability in observed maternal talk to children, even within low-income groups (DeTemple \& Snow, 1996; Pan \& Rowe, 1999). These analyses complement research findings based on observer ratings (Roberts et al., 1999) and raise two other issues: how stable individual mothers are in the communicative input they offer children over toddlerhood, and what specific factors relate to variability in maternal input.

\section{Change Over Time in Communicative Input}

Results of this study indicate that between child ages 14 and 36 months, both the amount and lexical diversity of talk mothers address to children on average increases over time. This change in maternal verbal input may be responsive to factors such as child age or language ability. Analyses revealed that $40 \%$ of the within-person variation in maternal tokens and $68 \%$ of the within-person variation in maternal types was explained by child age. For each individual mother the effect of child age on maternal word types was stronger than the effect on tokens. Thus, as a child matures (and presumably improves in language abilities), a specific mothers' increase in the diversity of words she directs to her child is more related to the child's age than is her increase in amount of talk overall. It may be that general maternal talkativeness is a relatively stable trait that increases during the early childhood years merely because children are much more communicative at age 3 than they are at age 1, whereas the increase in lexical diversity of talk may be more clearly linked to the child's increase in specific language abilities. If this is the case, it would be interesting to follow families longer to determine whether change over time in maternal tokens levels off at some point once specific styles of mother - child conversation be- 
come established for each dyad. Given that vocabulary acquisition is a continuous process reaching far beyond the early childhood years, we would expect the diversity of vocabulary mothers use with children to continue to increase, possibly more gradually with time.

Clearly, children of the same age may have very different language skills. Therefore, one limitation of this study is that in using child age as a measure of time, we may not have captured variation uniquely explained by child language ability. At the same time, using any measure of child language ability based on the same mother - child interaction (e.g., number of word types produced by the child) would have introduced other complications, in particular the problem of determining directionality of effects. Given the results presented here and the relatively new advances in research methods available for longitudinal developmental research (Singer \& Willett, 2003), we encourage further investigation of the change/stability in communicative input to children of varying language abilities over the first several years of life. This may be particularly important as we continue to address the role of communicative input in diverse samples where different sets of beliefs or factors relate to how mothers communicate with their children. Additionally, this work should extend to the realm of nonverbal interaction, as properties of nonverbal communication may be more or less stable over time than are properties of speech. For example, an examination of use of maternal pointing gestures with families from this same sample (Rowe, 2003) showed that on average mothers did not increase over time in their use of pointing, suggesting that pointing is a more stable trait or interactional style, whereas amount and lexical diversity of maternal talk are more responsive to child age and/or developing language ability.

\section{Predictors of Variation in Communicative Input}

We found that education, one traditional indicator of social class, explained some of the variation in maternal verbal input even within this low-income sample, thus extending previous work with middle- and working-class samples (e.g., Lawrence \& Shipley, 1996; Hoff-Ginsberg, 1992). That is, more educated low-income mothers talked more and used more diverse vocabulary with their toddlers than did less educated mothers. We do not know whether these differences would also extend to mothers' talk with other adults (Hoff-Ginsberg, 1991).

The differing effects of education and literacy skills on variation in the two communicative input variables studied deserve further discussion. To recap, in the final models we found that (1) maternal education was a significant predictor of amount of talk (controlling for maternal depression 
and age) and (2) both maternal education and language/literacy skills significantly predicted lexical diversity (controlling for maternal age). Thus, although educational experience appears to influence both amount and diversity of talk with children, prediction of lexical diversity is improved by consideration of low-income mothers' language/literacy skills (skills that are only moderately associated with education, $r=.36$ ). Recall that the language/literacy measure used here was a composite of mothers' scores on the WAIS and the WJ. Arguably, both these measures tap vocabulary skill. The WAIS itself is a vocabulary scale and is often used as a measure of verbal IQ. Presumably individuals who score high on the WAIS have larger vocabularies and lexical facility to draw on, even in conversation with very young children. The WJ letter - word identification task, although a literacy measure, focuses on word-level skills. Given the relatively deep orthography of English, word recognition (decoding) is likely facilitated by familiarity with the meanings and spelling of words being read. Both tasks, then, tap vocabulary knowledge. As research by Stanovich and colleagues (Stanovich \& Cunningham, 1992; West \& Stanovich, 1991) indicated, vocabulary skills can be enhanced through language- and literacy-related activities outside of school, as well as through school-based instruction. They reported that reading and incidental print exposure predict vocabulary, cultural literacy, and spelling, controlling for academic ability. The positive association observed in this study between maternal age and language/literacy skills suggests that what is being tapped is not simply natural verbal ability but also vocabulary skill acquired with age and experience both in and out of school.

This leads us to several limitations of this study regarding the education and language and literacy findings. First, we did not include information on maternal language and literacy practices in our models presented here. Information on the amount and type of reading mothers engage in is clearly worth considering. Second, for the purposes of our analyses it was most appropriate statistically to combine the WAIS and the WJ measures into one variable or predictor (language and literacy skills). However, as it would be useful to understand the separate effects of each variable to help determine whether it is vocabulary skill per se, basic literacy skills, or a combination of both that relate to maternal lexical diversity, we examined each predictor separately in an additional final model. Neither vocabulary nor literacy skills predicted maternal tokens when we controlled for the other variables already in the final model. This was not surprising, as the literacy composite itself was not a significant predictor of maternal talkativeness. In the final model predicting maternal types, when we removed the literacy composite and inserted the separate vocabulary and literacy measures, only the basic literacy measure (i.e, the WJ) was significant. The 
goodness of fit of the model was almost identical to that of the final model presented in Table 3. Thus, it appears that it is mothers' basic literacy skills rather than vocabulary IQ that is driving the association between language and literacy skills and the diversity of vocabulary used with children.

We found here that maternal depression was related to amount of maternal talk but not to the diversity of maternal vocabulary. The negative effect of depression on amount of talk replicates findings from other studies. For example, in a recent meta-analysis on maternal depression and parenting behavior, Lovejoy and colleagues (2000) cited at least 12 studies in which more depressed mothers were found to vocalize less with their young children. Our findings regarding amount of talk are in keeping with this literature. Given the symptoms of disengagement, withdrawal, and lethargy commonly associated with depression, it follows that such symptoms would result in a decrease in maternal talk. The symptoms of depression often lead to slowed speech and increased periods of silence between phrases that result in the reduction of talk. Furthermore, talk such as fillers or repetitions that is not as essential to the communicative exchange, particularly in the context of communicating animated and positive emotion, is often missing in maternal - child exchanges with depressed mothers (Cohen \& Tronick, 1989; Field, 1995). Such depressive symptoms would not, however, be expected to impact the basic sophistication in the mothers' vocabulary use. Thus, our findings are in keeping with but extend the literature on talk of depressed mothers with their young children.

One finding that was similar for both amount and lexical diversity of talk was their positive association with maternal age. As a reminder, the mothers in this sample ranged from 16 to 41 years of age with a mean of 25.5 years. More specifically, the middle $50 \%$ of women were between 20 and 30 years, yet 22 women were between 14 and 19 and an additional 14 women were 35 years or older. We found that older mothers talked more and used more diverse vocabulary than did younger mothers during interaction with their children. In each case, the main effect of maternal age on input was significant, even after controlling for maternal education and/or language and literacy skills; therefore it was not merely that older women were more educated or higher skilled and thus communicated more. In addition we found no effect of birth order on maternal communicative input and no interaction between birth order and age. Thus the effect of age was not due to the children of older women being later born rather than firstborn. Similar results have been found in other studies. For example, Culp et al. (1996) found that adolescent mothers ( $M=15$ years, 4 months) spoke significantly fewer words to their infants than did older mothers $(M=23$ years, 7 months) when mothers were matched on other characteristics such as education and ethnicity. 
We have no definitive explanation for why older women communicated more and used more diverse vocabulary. We can only offer the hypothesis that older mothers, with more experience in the world, may have more experience communicating in general, and may have different beliefs about child development than do younger mothers, prompting them to engage in more communication with their children. There is some evidence in support of this hypothesis, as significant differences have been found between adolescent mothers and older mothers using the Knowledge of Infant Development Inventory (KIDI, MacPhee, 2002; Ruchala \& James, 1997), a measure of maternal beliefs about child development that has been found to relate to maternal vocabulary use during interaction with children (Bornstein et. al., 1998). Of course, this hypothesis needs to be tested empirically before any conclusions can be drawn about reasons for the relation between maternal age and communicative input.

\section{Limitations and Directions for Future Research}

This study is limited by the fact that the low-income sample is not typical of American low-income families. In particular, this sample included very few ethnic- or linguistic-minority families and was drawn from a rural area of New England. Therefore, the results presented here cannot be generalized to all American low-income families. Furthermore, although the sample size used in this study is large in comparison to most studies of mother - child interaction, it is just large enough for the statistical methods employed here. Additional waves of data and/or more participants might result in better fitting models and possibly more reliable estimates. Finally, none of our predictors or control variables explained variation in change over time in maternal tokens or types, even though there was significant variance in growth to explain. Therefore, other factors, possibly more child-centered measures, should be investigated in future work. Future research would also benefit from employing similar analyses to determine whether the same factors relate to maternal communicative input in samples from a variety of ethnicities and cultures. Additionally, similar work with fathers and other caregivers would provide broader insights into the communicative environments available to children during the early language-learning years.

\section{AFFILIATIONS AND ADDRESSES}

Meredith Rowe, University of Chicago, Department of Psychology, 5848 S. University Ave (Box 6), Chicago, IL 60637-1584. Email: rowemer@ 
uchicago. edu. Barbara Alexander Pan and Catherine Ayoub are at Harvard University.

\section{ACKNOWLEDGMENTS}

The findings reported here are based on research conducted as part of the national Early Head Start Research and Evaluation Project funded by the Administration on Children, Youth, and Families, U.S. Department of Health and Human Services through Grant 90YF0009 to Harvard University Graduate School of Education. The research was conducted in collaboration with Early Education Services in Brattleboro, VT, one of 17 programs participating in the national Early Head Start study. The authors are members of the Early Head Start Research Consortium. The Consortium consists of representatives from 17 programs participating in the evaluation, 15 local research teams, the evaluation contractors, and ACYF. The content of this publication does not necessarily reflect the views or policies of the Department of Health and Human Services. This article formed part of the first author's Ed.D. dissertation. The authors express their gratitude to their program partners and to the participating families. We thank M. Bornstein and reviewers for helpful comments, and C. Snow and J. Singer for feedback and assistance.

\section{REFERENCES}

Barnes, S., Gutfreund, M., Satterly, D., \& Wells, G. (1983). Characteristics of adult speech which predict children's language development. Journal of Child Language, 10, 65-84.

Belle, D. (1990). Poverty and women's mental health. American Psychologist, 45, 385-389.

Bellinger, D. (1980). Consistency in the pattern of change in mothers' speech: Some discriminant analyses. Journal of Child Language, 7, 469-487.

Bettes, B. A. (1988). Maternal depression and motherese: Temporal and intonational features. Child Development, 59, 1089-1096.

Borduin, C. M., \& Henggeler, S. W. (1981). Social class, experimental setting, and task characteristics as determinants of mother-child interaction. Developmental Psychology, 17, 209-214.

Bornstein, M. H., Haynes, M. O., \& Painter, K. M. (1998). Sources of child vocabulary competence: A multivariate model. Journal of Child Language, 25, 367-393.

Bornstein, M. H., Tamis-LeMonda, C. S., \& Haynes, M. O. (1999). First words in the second year: Continuity, stability, and models of concurrent and predictive correspondence in vocabulary and verbal responsiveness across age and context. Infant Behavior and Development, 22, 65-85.

Breznitz, Z., \& Sherman, T. (1987). Speech patterning of natural discourse of well and depressed mothers and their young children. Child Development, 58, 395-400.

Cohen, J. F., \& Tronick, E. Z. (1989). Specificity of infant's response to mother's affective behavior. Journal of the American Academy of Child and Adolescent Psychiatry, 28, 242-248.

Corkum, V., \& Dunham, P. (1996). The Communicative Development Inventory-WORDS Short Form as an index of language production. Journal of Child Language, 23, 515-528. 
Cross, T. (1977). Mothers' speech adjustments: The contribution of selected child language variables. In C. E. Snow \& C. A. Ferguson (Eds.), Talking to children: Language input and acquisition (pp.151-188). Cambridge, England: Cambridge University Press.

Culp, A. M., Osofsky, J. D., \& O'Brien, M. (1996). Language patterns of adolescent and older mothers and their one-year-old children: A comparison study. First Language, 16, 61-75.

DeTemple, J. M., \& Snow, C. E. (1996). Styles of parent-child book-reading as related to mothers' views of literacy and children's literacy outcomes. In J. Shimron (Ed.), Literacy and education: Essays in honor of Dina Feitelson (pp. 49-68). Cresskill, NJ: Hampton.

Dickinson, D. K., \& Tabors, P. O. (2001). Beginning literacy with language. Baltimore, MD: Brookes.

Field, T. (1995). Infants of depressed mothers. Infant Behavior and Development, 18, 1-3.

Hampson, J., \& Nelson. K. (1993). The relation of maternal language to variation in rate and style of language acquisition. Journal of Child Language, 20, 199-215.

Hart, B., \& Risley, T. R. (1995). Meaningful differences in the everyday experience of young American children. Baltimore, MD: Brookes.

Hoff, E. (2003). The specificity of environmental influence: Socioeconomic status affects early vocabulary development via maternal speech. Child Development, 74, 1368-1378.

Hoff, E., Laursen, B., \& Tardif, T. (2002). Socioeconomic status and parenting. In M. H. Bornstein (Ed.), Handbook of parenting, Vol. 2: Biology and Ecology of Parenting (2nd ed., pp. 231-252). Mahwah, NJ: Lawrence Erlbaum Associates, Inc.

Hoff, E., \& Naigles, L. (2002). How children use input to acquire a lexicon. Child Development, $73,418-433$.

Hoff-Ginsburg, E. (1991). Mother-child conversations in different social classes and communicative settings. Child Development, 62, 782-796.

Hoff-Ginsberg, E. (1992). How should frequency in input be measured? First Language, 12, 233-244.

Hoff-Ginsberg, E. (1994). Influences of mother and child on maternal talkativeness. Discourse Processes, 18, 105-117.

Hoff-Ginsberg, E. (1998). The relation of birth order and socioeconomic status to children's language experience and language development. Applied Psycholinguistics, 19, 603-29.

Huttenlocher, J., Haight, W., Bryk, A., Seltzer, M., \& Lyons, T. (1991). Early vocabulary growth: Relation to language input and gender. Developmental Psychology, 27, 236-48.

Jones, C., \& Adamson, L. B. (1987). Language use in mother-child and other child-sibling interactions. Child Development, 58, 356-366.

Lawrence, V., \& Shipley, E. (1996). Parental speech to middle- and working-class children from two racial groups in three settings. Applied Psycholinguistics, 17, 233-255.

Leaper, C., Anderson, K. J., \& Sanders, P. (1998). Moderators of gender effects on parents' talk to their children: A meta-analysis. Developmental Psychology, 34, 3-27.

Lovejoy, M. C., Graczyk, P. A., O’Hare, E., \& Newman, G. (2000). Maternal depression and parenting behavior: A meta-analytic review. Clinical Psychology Review, 20, 561-592.

MacPhee, D. (2002). Knowledge of infant development inventory: Manual (Rev. ed.). Fort Collins, CO: Colorado State University.

MacWhinney, B. (2000). The CHILDES project: Tools for analyzing talk. Mahwah, NJ: Lawrence Erlbaum Associates, Inc.

McCartney, K., Robeson, W., Jordan, E., \& Mouradian, V. (1991). Mothers' language with firstand second-born children: A within-family study. In K. Pillemer \& K. McCartney (Eds.), Parent-child relations throughout life (pp. 125-142). Hillsdale, NJ: Lawrence Erlbaum Associates, Inc.

National Institute of Child Heath and Human Development Early Child Care Research Network. (2000). The relation of child care to cognitive and language development. Child Development, 71, 960-980. 
Ninio, A. (1980). Picture-book reading in mother-infant dyads belonging to two subgroups in Israel. Child Development, 51, 587-590.

Pan, B. A., \& Rowe, M. L. (1999, July). Sources of variation in the amount mothers talk and gesture in interaction with their 14-month-old children. In P. O. Tabors (Chair), Contraints and beliefs: Influences of maternal and child characteristics on interaction during book reading with toddlers, preschoolers, and beginning readers from low-income families. Symposium conducted at the eighth meeting of the International Congress for the Study of Child Language, San Sebastian, Basque Country, Spain.

Pan, B. A., Rowe, M. L., Singer, J. D., \& Snow, C. E. (2004). Maternal correlates of child vocabulary growth in low-income families. Manuscript submitted for publication.

Pan, B. A., Rowe, M. L., Spier, E., \& Tamis-LeMonda, C. (2004). Measuring productive vocabulary of toddlers in low-income families: Concurrent and predictive validity of three sources of data. Journal of Child Language, 31, 587-608.

Radloff, L. S. (1977). The CES-D scale: A self report depression scale for research in the general population. Applied Psychological Measurement, 1, 385-401.

Roberts, J. E., Burchinal, M., \& Durham, M. (1999). Parents' report of vocabulary and grammatical development of African American preschoolers: Child and environmental associations. Child Development, 70, 92-106.

Rowe, M. L. (2003). A longitudinal investigation of factors related to maternal communicative input and child vocabulary growth in low-income American families. Unpublished doctoral dissertation, Harvard University Graduate School of Education, Cambridge, MA.

Rowe, M. L., Coker, D., \& Pan, B. A. (2004). A comparison of fathers' and mothers' talk to toddlers in low-income families. Social Development, 13, 278-291.

Ruchala, P. L., \& James, D. C. (1997). Social support, knowledge of infant development, and maternal confidence among adolescent and adult mothers. Journal of Obstetrical, Gynecological, and Neonatal Nursing, 26, 685-689.

Singer, J. D., \& Willett, J. B. (2003). Applied longitudinal data analysis: Modeling change and event occurrence. New York: Oxford University Press.

Snow, C. E. (1972). Mothers' speech to children learning language. Child Development, 43, $549-565$.

Snow, C. E., Pan, B. A., Imbens-Bailey, A., \& Herman, J. (1996). Learning how to say what one means. Social Development, 5, 56-84.

Stanovich, K. E., \& Cunningham, A. E. (1992). Studying the consequences of literacy within a literate society: The cognitive correlates of print exposure. Memory \& Cognition, 20, 51-68.

Tomasello, M., \& Stahl, D. (2004). Sampling children's spontaneous speech: How much is enough? Journal of Child Language, 31, 101-121.

U. S. Department of Health and Human Services, Administration for Children and Families. (2001, June). Building their futures: How Early Head Start programs are enhancing the lives of infants and toddlers in low-income families. Retrieved February 13, 2004, http:/ / www.acf.hhs. gov/programs/opre/ehs/ehs_resrch/index.html

Vandell, D. L. (1979). A microanalysis of toddlers' social interaction with mothers and fathers. Journal of Genetic Psychology, 134, 299-312.

Wechsler, D. (1981). Manual for Wechsler Adult Intelligence Scale-Revised. San Antonio, TX: The Psychological Corporation.

Weizman, Z. O., \& Snow, C. E. (2001). Lexical input as related to children's vocabulary acquisition: Effects of sophisticated exposure and support for meaning. Developmental Psychology, 37, 265-279.

West, R. F., \& Stanovich, K. E. (1991). The incidental acquisition of information from reading. Pscyhological Science, 2, 325-329.

Woodock, R. (1978). Development and standardization of the Woodcock-Johnson psychological educational battery. Hingham, MA: Teaching Resources. 